\title{
PREVISÃO DO TEMPO DE CAMPANHA DE TROCADORES DE CALOR DO SISTEMA DE GÁS DE RECICLO DE REATORES DE POLIMERIZAÇÃO DE ETENO EM LEITO FLUIDIZADO
}

\author{
K. P. N. PIRES ${ }^{1,2}$, J. B. V. BASTOS 2 , J. M. NIKIEL ${ }^{2,3}$ \\ ${ }^{1}$ Universidade Federal Fluminense, Faculdade de Engenharia Química \\ 2 Braskem S.A \\ ${ }^{3}$ Universidade Federal do Rio de Janeiro, Doutorando na Escola de Química \\ E-mail para contato: knossar@id.uff.br
}

\begin{abstract}
RESUMO - Redução de carga, aumento do consumo energético e parada indevida do processo são apenas algumas das consequências do não acompanhamento das variáveis de processo que regem a operação de um trocador de calor. Portanto, um acompanhamento criterioso é necessário para se evitar situações de aumento do custo de produção e/ou descontinuidades de uma unidade industrial. A perda de carga do trocador, por exemplo, é uma variável que merece atenção especial. A elaboração do presente trabalho se mostrou de grande utilidade por fornecer uma previsão do tempo de campanha de um trocador de calor chave para o processo estudado, tal previsão aperfeiçoa a gestão de custos variáveis da unidade na medida em que permite a realização de um planejamento de substituição e limpeza do equipamento. A partir da ferramenta desenvolvida, além do tempo de campanha, é possível estimar a quantidade de tubos obstruídos bem como calcular os dias de operação que foram perdidos devido a eventos de processo. Tal ferramenta foi desenvolvida através de uma regressão linear que, partindo de dados históricos da planta, foi aplicada a uma equação conhecida relacionando a perda de carga no interior dos tubos com o tempo.
\end{abstract}

\section{INTRODUÇÃO}

Uma das tecnologias existentes para a produção do polietileno é a que utiliza um reator de leito fluidizado presente em um sistema de gás em recirculação. Este tipo de tecnologia é comercialmente conhecido como Fase Gás ou UNPOL. Esse sistema, representado pela Figura 1, é economicamente mais viável quando comparado aos demais processos de polimerização de eteno visto que é mais simples por conter apenas um reator operando em pressões mais baixas o que diminui o risco de acidentes de maior gravidade. Além disso, ele dispensa unidades de recuperação de solventes sendo isso de grande ganho ambiental, como apresentado por McAuley (1990 apud Tait, 1989) em seu trabalho.

O sistema reacional do processo consiste basicamente de um reator de leito fluidizado com uma placa distribuidora em seu interior, um trocador de calor e um compressor. A alimentação de matérias primas para o reator é realizada em dois pontos, um a montante do compressor que contém os gases inertes, hidrogênio e eteno e outra a jusante composta pelas substâncias menos voláteis como os comonômeros, buteno ou hexeno, e o agente de condensação. O compressor de gás de reciclo é responsável por vencer a perda de carga do sistema mantendo o gás em recirculação. $\mathrm{O}$ gás em recirculação passa por um trocador de 


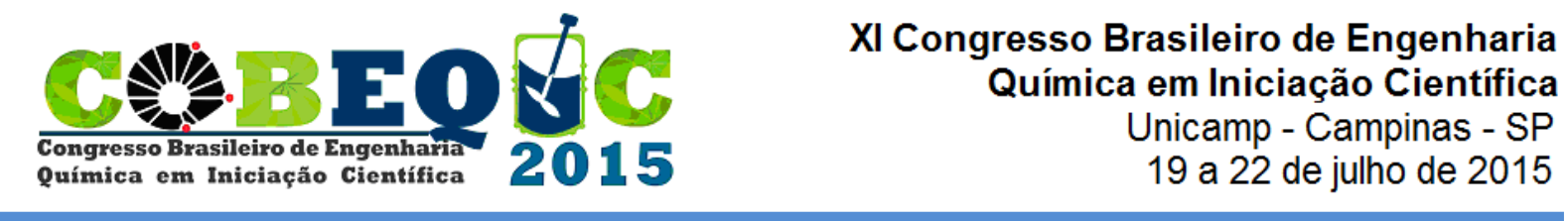

calor que é responsável pela remoção do calor da reação de polimerização. No trocador os compostos de maior peso molecular condensam. A parcela de gás condensada ao adentrar no reator vaporiza instantaneamente conferindo ao sistema uma maior capacidade de troca térmica e consequente maior capacidade produção, visto que a taxa de produção é diretamente proporcional a capacidade de remoção de calor do sistema. O modo de operação com condensação parcial do gás de reciclo é conhecido como Condensação Induzida. Em seu trabalho Gambetta (2001) deixa clara a importância de um controle de temperatura no reator devido ao risco de fusão das partículas de polietileno, principalmente os de baixa densidade, podendo levar a formação de aglomerados. No interior do reator, a mistura gasosa entra em contato com o catalisador que é alimentado continuamente (McAuley, 1990). A fluidização do leito é responsável pela dispersão do catalisador e, portanto, evita a formação de possíveis pontos quentes causados pelo acúmulo de catalisador (Gambetta, 2001).

A resina polimérica é descarregada em um vaso pulmão e posteriormente é enviada a um local para remoção dos gases sobressalentes. Após retirada dos gases, a resina é fundida, transformada em pellet e ensacada para comercialização (Sousa, 2005).

Figura 1 - Produção de polietileno em um reator de leito fluidizado (Sousa, 2005).

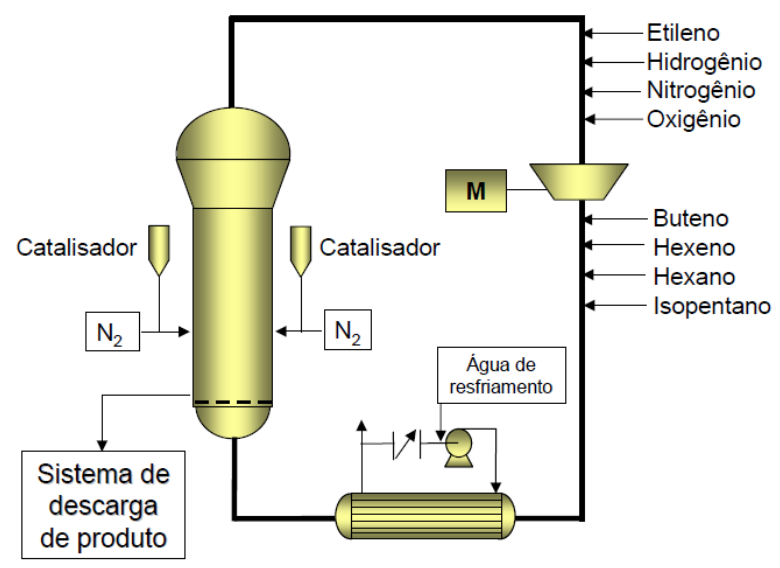

O presente estudo teve como foco o trocador de calor do sistema de gás de reciclo da reação. $\mathrm{O}$ equipamento consiste em um modelo casco-tubos em que a corrente gasosa a ser resfriada passa pelos tubos e a água de resfriamento pelo casco.

Mukherjee (2001) apresenta a Equação 1 onde o tempo de campanha de uma placa distribuidora de reatores fase gás pode ser previsto de maneira satisfatória. Neste trabalho se pretende verificar a possibilidade desta equação ser utilizada para prever o tempo de campanha do trocador de calor do gás de reciclo. Tal previsão permitirá um maior planejamento das equipes de manutenção, operação e engenharia quanto a realização da substituição e limpeza do equipamento. Também permite que aconteça um acompanhamento mais criterioso das condições do processo como, por exemplo, a variação do diferencial de pressão em diferentes resinas. Além disso, possibilita analisar o impacto que um evento ocorrido na planta tenha influenciado na campanha do trocador.

\section{OBJETIVO}


Desenvolver um modelo que estime o tempo de campanha do trocador de calor do sistema de gás de reciclo do reator de polimerização de eteno para apoiar as equipes de operação e manutenção da unidade de produção de polietileno da Braskem em Duque de Caxias.

\section{METODOLOGIA}

Inicialmente, foi verificada a disponibilidade dos dados a serem utilizados no desenvolvimento do modelo. De posse dos dados históricos partiu-se para a etapa de tratativa dos mesmos. Foram desprezados os dados em que o reator não estava em sua total capacidade de funcionamento e também foram desprezados os "outliers" de transição de produto que apareciam na forma de frequentes picos como pode ser observado na Figura 2. A Equação 1 foi então linearizada para que o tempo ficasse dependente do diferencial de pressão.

Figura 2 - Gráfico no início da tratativa dos dados

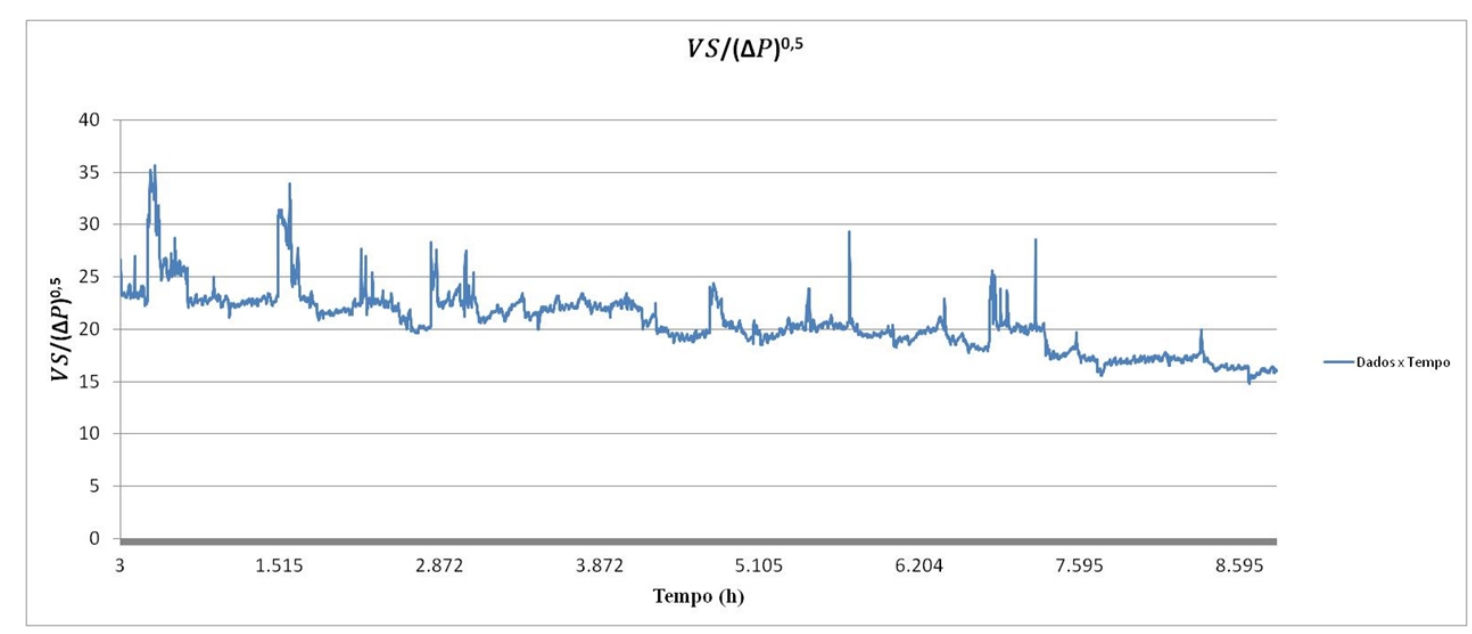

Após todo o tratamento dos dados chegou-se a uma função que relaciona o comportamento do diferencial de pressão com o tempo. Realizou-se procedimento de estimação de parâmetros para encontrar as constantes da Equação 1. Desta forma, foi obtida a equação final que calcula o tempo de campanha do trocador de calor.

\section{RESULTADOS}

No gráfico da Figura 3 é possível verificar uma tendência coerente do comportamento do diferencial de pressão com o tempo. Sabe-se que seus valores mostram um aumento no decorrer da campanha visto que o pó circulante no sistema tende a se depositar no interior dos tubos conferindo uma barreira à passagem da corrente gasosa.

Figura 3 - Comportamento do diferencial de pressão com o tempo 

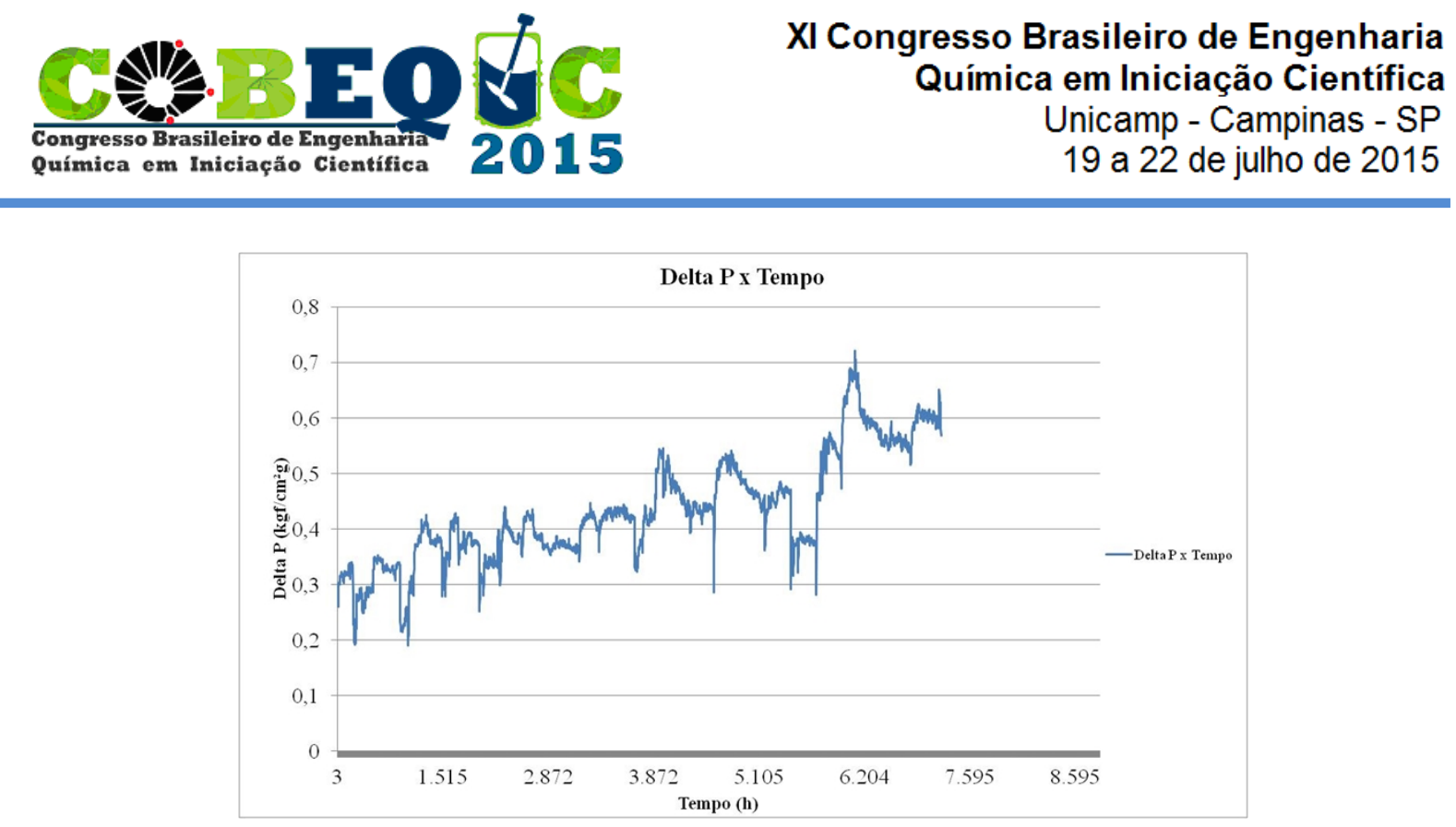

A Figura 2 contém o gráfico com os valores obtidos a partir da equação linearizada e ilustra o comportamento da perda de carga com o tempo. Pode-se observar que, apesar de terem sido retiradas as oscilações na operação do reator, o gráfico ainda apresenta picos o que, como citado anteriormente, reflete o diferencial de pressão quando há transições para mudanças de produto. Quando há transição de produto no reator a densidade da corrente gasosa se altera devido a variações na composição dos gases nela presentes, esta variação de densidade impacta significativamente a perda de carga do trocador. Para a retirada dos dados que destoavam da tendência do cálculo foram traçadas retas paralelas à de seu comportamento (Figura 4). A razão para utilização dessas retas foi extrair os pontos que caracterizavam as transições de produto. As retas foram deslocadas tanto para cima quanto para baixo em relação a intercepção da reta central no eixo das ordenadas.

Figura 2 - Gráfico com as retas para tratamento de dados

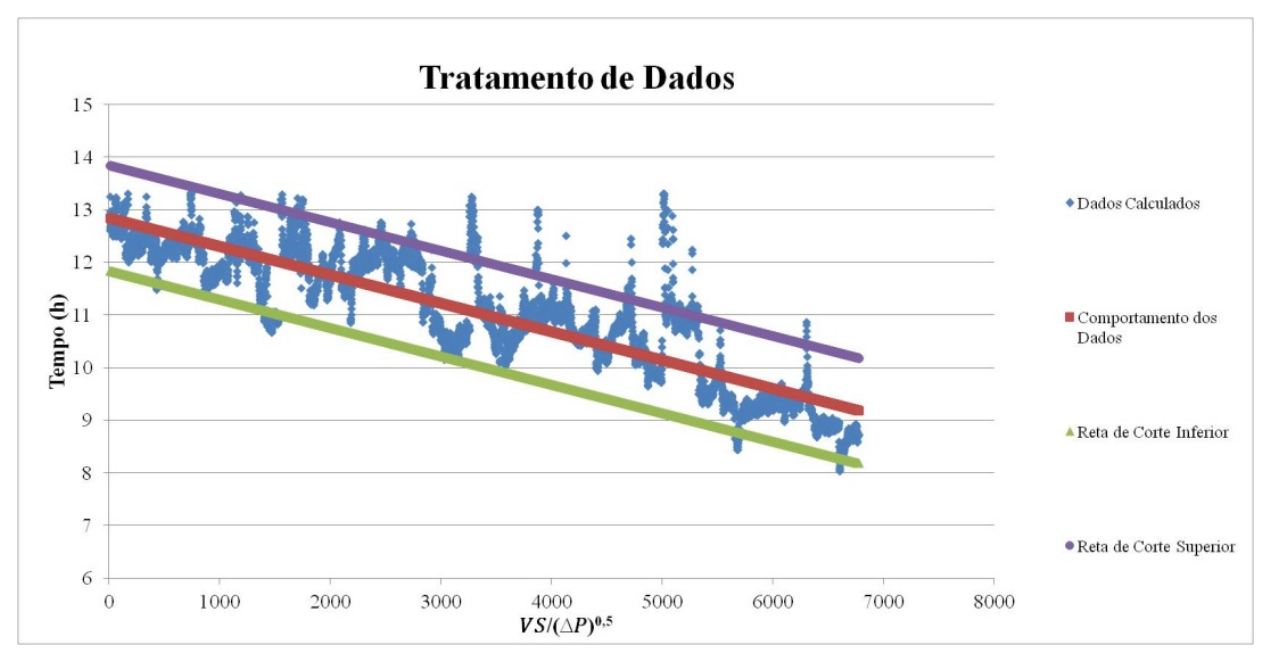

Após expurgadas as transições chegou-se, finalmente, aos resultados apresentados na Figura 5. Como observado, o coeficiente de determinação ficou bem próximo da unidade o que confere ao modelo uma boa representatividade por uma equação de uma reta.

Figura 3 - Gráfico com dados tratados e reta de tendência 

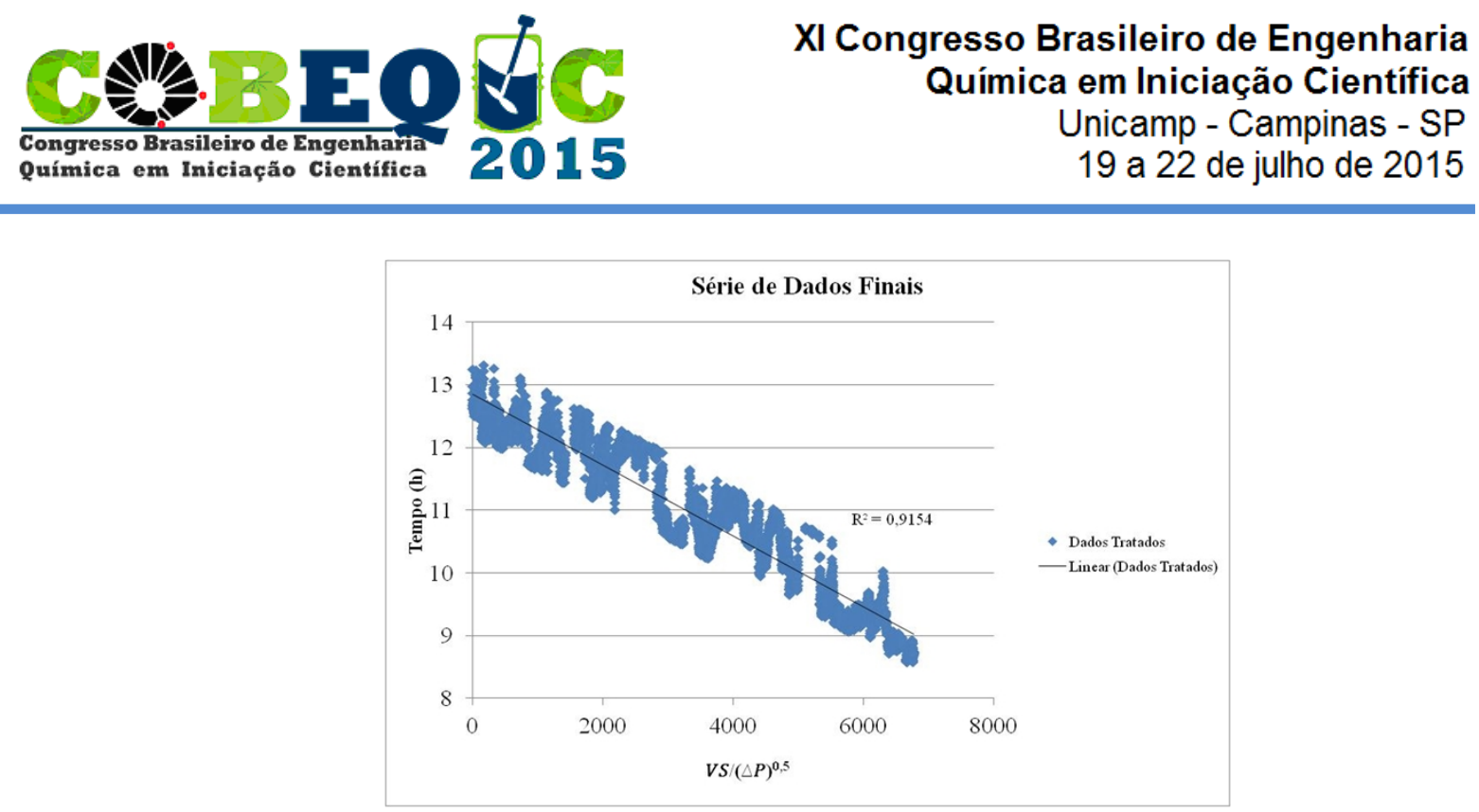

Para o acompanhamento contínuo das condições de operação do trocador foi criada uma planilha em Excel que contém uma tabela dinâmica em que os dados da planta são atualizados automaticamente. As Tabelas apresentadas na Figura 6 correspondem a uma campanha do trocador de calor. A planilha desenvolvida é a ferramenta de apoio que fornece informações como o tempo de campanha que é função de um delta de pressão considerado como sendo o ideal para substituição do trocador. Também é realizado estimativa do número dias em que o trocador já operou desde quando retornou ao sistema (tal informação pode ser comparada com o número real de dias de operação e a diferença, quando menor, deve ser investigada e identificada a possível causa para redução do tempo de operação do equipamento). Além disso, os dias restantes de operação e previsão de troca do equipamento são apresentados permitindo a realização de um planejamento de manutenção com maior grau de assertividade. Observa-se que o diferencial de pressão (Delta P) esperado de campanha (calculado pelo modelo) é bem próximo do diferencial médio realizado. Com uma precisão de 99,5\% é possível concluir que o modelo atende ao objetivo a que foi proposto.

Figura 4 - Tabelas para acompanhamento da unidade
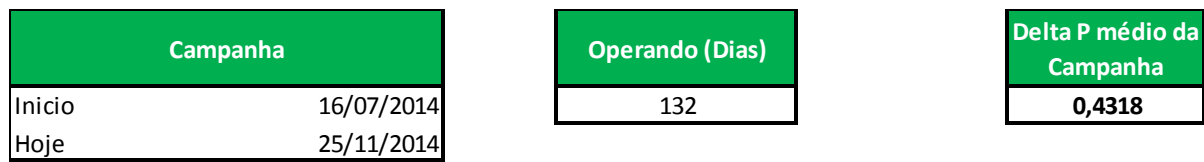

\begin{tabular}{|lr|}
\hline \multicolumn{2}{|c|}{ Tempo Total de Campanha } \\
\hline Delta P & 0,7 \\
tempo (h) & 7392,63 \\
\hline Dias operados: & 303,8 \\
\hline \multicolumn{2}{|c|}{} \\
\hline Dias Restantes: & 171,8 \\
\hline Previsão de Troca & $15 / 05 / 2015$ \\
\hline
\end{tabular}

\begin{tabular}{|c|c|}
\hline \multicolumn{2}{|c|}{ Tempo Estimado de Campanha } \\
\hline $\begin{array}{l}\text { Delta P } \\
\text { tempo (h) }\end{array}$ & $\begin{array}{r}0,4318 \\
3219,434 \\
\end{array}$ \\
\hline Dias operados previst & 134,15 \\
\hline Dias perdidos de ope & 2,15 \\
\hline Dias Restantes: & 169,7 \\
\hline Previsão de Troca & $13 / 05 / 2015$ \\
\hline
\end{tabular}

\section{CONCLUSÃO}




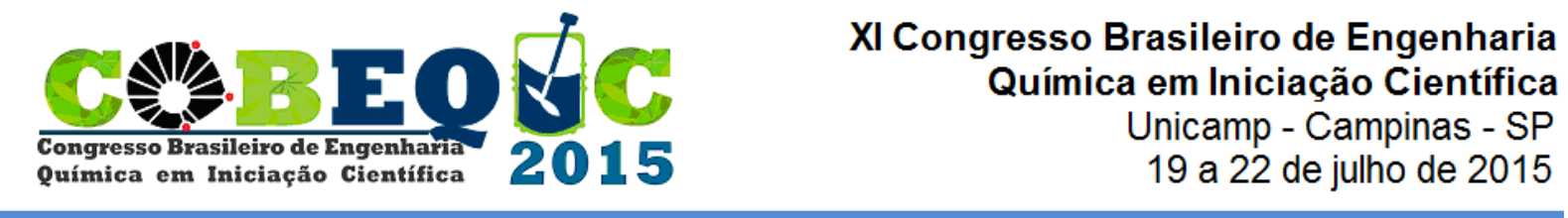

A implementação do trabalho permite estimar o tempo total que a planta pode operar até chegar a um diferencial de pressão limite no trocador de calor bem como, um acompanhamento criterioso das condições de operação do sistema reacional. Além disso, permite avaliar qual foi o impacto de um evento no processo através da quantificação do número de dias de operação perdidos. Tais previsões conferem aos setores interessados, como Manutenção, Engenharia de Processos e Operação, uma melhoria expressiva no planejamento de troca do equipamento, otimizando custos e aumentado a segurança operacional da planta.

\section{EQUAÇÕES}

$$
\Delta P=k \cdot \frac{(V S)^{2}}{(N o-m \cdot t)^{2}} \quad \text { Equação } 1
$$

\section{NOMENCLATURA}

$\mathrm{k}$ : constante determinada a partir de dados operacionais;

m: velocidade de obstrução dos furos do trocador $\left(\mathrm{h}^{-1}\right)$

No: número de tubos do trocador de calor

P: pressão $\left(\mathrm{kgf} / \mathrm{cm}^{2} \mathrm{~g}\right)$

t: tempo da campanha $(\mathrm{h})$

VS: velocidade superficial do gás de reação no leito fluidizado $(\mathrm{m} / \mathrm{s})$

\section{REFERÊNCIAS}

GAMBETTA, R.; Modelagem e Simulação de Reatores em Leito Fluidizado; Dissertação de Mestrado, Universidade Federal do Rio Grande do Sul - Porto Alegre, 2001.

MCAULEY, K. B.; MACGREGOR, J. F.; HAMIELEC, A. E.; A Kinetic Model for Industrial Gas-Phase Ethylene Copolymerization; AIChE Journal; June 1990.

MUJHERJEE, A; Modelo Exponencial para Predição do Tempo de Campanha da Placa Distribuidora. Relatório Técnico - Braskem PE1-2001.

SOUSA, K. L.; Otimização de Reatores de Polimerização de Etileno em Fase Gás; UFBA; 2005

TAIT, P.J.; Monoalkene Polymerization: Ziegler-Natta and Transition Metal Catalysts; Chapter 1 in Comprehensive Polymer Science; eds. G. Allen and J.C. Bevington, Pergammon Press; 1989. 